\title{
Castleman's disease: A case report
}

\author{
Koustav Jana ${ }^{1}$, Roby Das', Ranajoy Ghosh ${ }^{2}$, Sukanta Ray \\ From ${ }^{1}$ Senior Resident, ${ }^{2}$ Professor, Department of Surgical Gastroenterology, ${ }^{3}$ Assistant Professor, Department of Gastrointestinal Pathology, SSKM \\ Hospital and Institute of Post Graduate Medical Education and Research, Kolkata, West Bengal, India
}

\begin{abstract}
Castleman's disease (CD) is a rare non-malignant lymphoproliferative disorder of uncertain etiology. Its localized variety presents with incidentally found mass or symptomatic mass, whereas other type presents with generalized lymphadenopathy with systemic manifestations. Here, we report the case of localized CD in a 46-year-old female who presented with a complaint of vague upper abdominal pain for the past 6 months. The patient was managed with surgical resection only. Microscopic examination confirmed the entity to be CD of hyaline vascular type. The patient was asymptomatic at 15 months follow-up.
\end{abstract}

Key words: Castleman's disease, Surgery, Tumor, Unicentric variety

$\mathrm{C}$ astleman's disease (CD) is a rare non-malignant lymphoproliferative disorder. Its true incidence and etiology are still unknown. Although case reports and series have been published since its description, presently, there is no consensus guideline regarding its diagnosis and management because of the rarity of the disease. Here, we describe a case of localized CD near the pancreatic tail region which was managed with surgery alone.

\section{CASE REPORT}

A 46-year-old lady presented with a complaint of vague upper abdominal pain for the past 6 months. It was gradual in onset and intermittent in nature. There were no significant aggravating or relieving factors. However, it was managed with intermittent oral analgesics and antacids. She was a known diabetic for the past 10 years. She had no other medical history or family history.

On systemic examination, she was normothermic with a recorded regular pulse of $80 / \mathrm{min}$ and blood pressure 130/80 mmHg. Physical local examination revealed deep-seated tenderness in the left subcostal region without any palpable mass, organomegaly, or peripheral lymphadenopathy.

Initial ultrasonography (USG) showed one hypoechoic lesion $(38 \mathrm{~mm} \times 34 \mathrm{~mm})$ near the tail of the pancreas. Further evaluation by contrast-enhanced computed tomography scan (CECT scan) revealed a large heterogeneously hypervascular mass near the pancreatic tail region measuring $3.73 \mathrm{~cm} \times 3.7 \mathrm{~cm}$

\section{Access this article online}

Received - 23 August 2020

Initial Review - 08 September 2020

Accepted - 02 October 2020

DOI: $10.32677 /$ IJCR.2020.v06.i10.009
(Fig. 1). No vascular involvement was noted. Findings of upper gastrointestinal endoscopy were normal. Routine investigations such as complete blood count, liver function tests, renal function tests, and electrolytes were found to be within normal range $(\mathrm{Hb}-11 \mathrm{gm} / \mathrm{dL}$, total count $-8900 / \mathrm{cc}$, bilirubin $-0.6 \mathrm{mg} / \mathrm{dL}$, serum glutamic oxaloacetic transaminase/serum glutamic pyruvic transaminase - 28/26 IU/L, alkaline phosphatase - $76 \mathrm{IU} / \mathrm{L}$, albumin $-3.8 \mathrm{~g} / \mathrm{dL}$, urea $-16 \mathrm{mg} / \mathrm{dL}$, creatinine $-0.8 \mathrm{mg} / \mathrm{dL}$, sodium - $137 \mathrm{mEq} / \mathrm{L}$, and potassium - $3.7 \mathrm{mEq} / \mathrm{L})$. Her serum CA 19-9 values was $18.73 \mathrm{U} / \mathrm{ml}$. A preoperative working diagnosis of a distal pancreatic tumor was made.

After adequate preoperative preparation, she was explored under general anesthesia. A $4 \mathrm{~cm} \times 4 \mathrm{~cm}$ hard mass was found at the inferior border of the body of the pancreas in retroperitoneum. It was neither involving the pancreas parenchyma or any other adjacent lymph node or structure. Intraoperative diagnosis of a distinctly enlarged lymph node was made and local excision was performed. She had an uneventful post-operative period and was discharged after 5 days.

On gross examination, it was a single globular mass measuring $4 \mathrm{~cm} \times 4 \mathrm{~cm} \times 1.5 \mathrm{~cm}$ with a fleshy gray-white cut surface. Microscopic examination revealed a lymph node with regressively transformed follicles. Follicular centers were surrounded by the "onion skin" of small lymphocytes. Penetrating hyalinized small vessels were present with an admixture of predominantly small lymphocytes and scattered plasma cells (Fig. 2). All these features were suggestive of CD of hyaline vascular (HV) type. Further CECT of the chest and neck did not reveal any lymphadenopathy.

Correspondence to: Koustav Jana, Department of Surgical Gastroenterology, SSKM Hospital and Institute of Post Graduate Medical Education and Research, 242 AJC Bose Road, Kolkata - 700 017, West Bengal, India. E-mail: koustavbsmc@gmail.com

(C) 2020 Creative Commons Attribution-NonCommercial 4.0 International License (CC BY-NC-ND 4.0). 


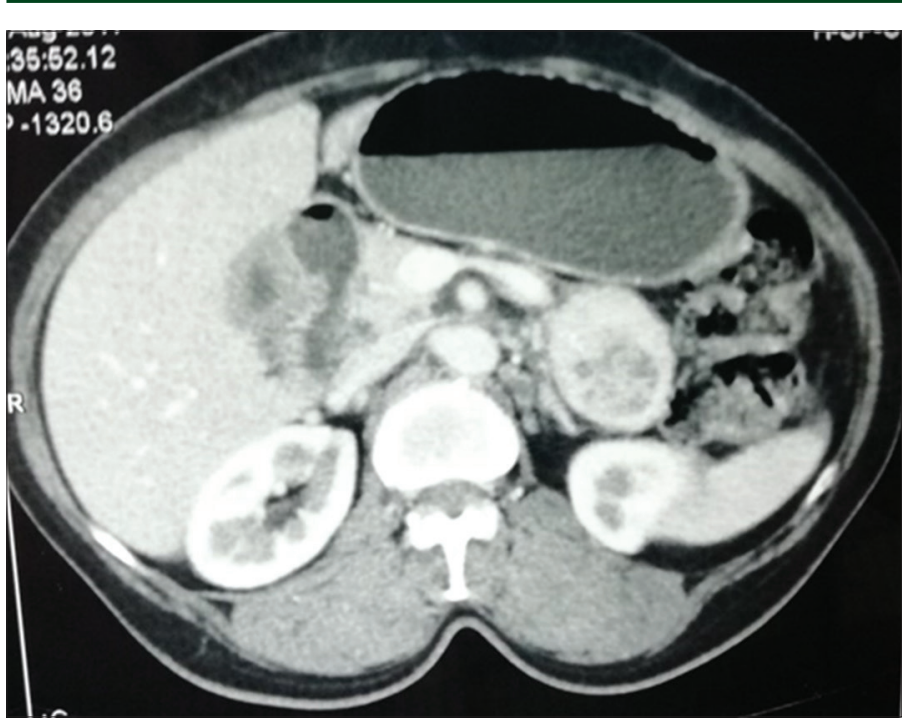

Figure 1: Computed tomography image (axial view) showing hypervascular tumor

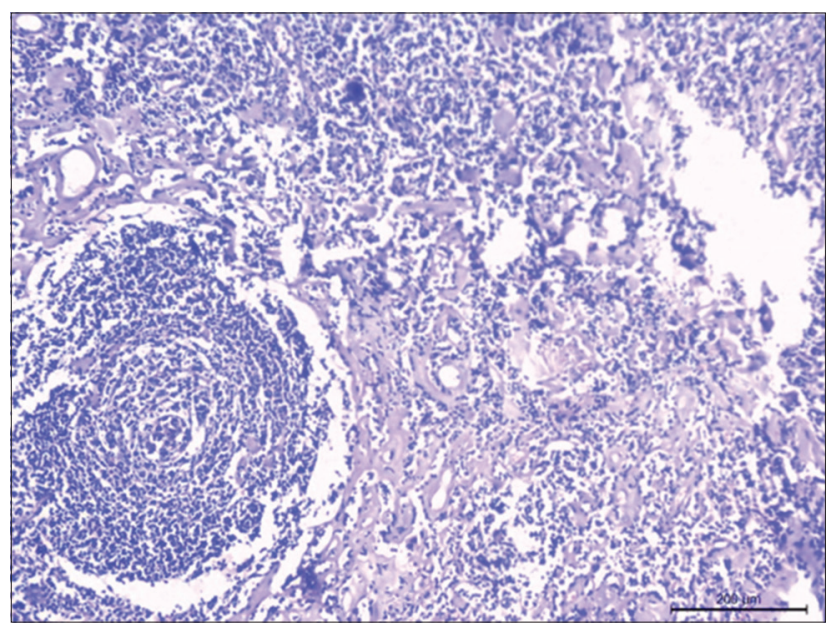

Figure 2: Hematoxylin and eosin $(10 \times)$ stained section showing lymph node with follicular center surrounded by the "onion skin" of lymphocytes

Immunohistochemical analysis was not feasible. She was asymptomatic at 15-month follow-up.

\section{DISCUSSION}

CD was first described by Benjamin Castleman in 1956 [1]. It is clinically classified into two types depending on the lymph nodal involvement - unicentric (single node involvement) and multicentric type. CD is also classified into three types depending on histologic findings as $\mathrm{HV}$, plasma cell, and mixed entity. HV type is reported to be the most common. Again HV-CD is most often found in indolent unicentric CD (UCD) tumors, whereas plasma cell variety is the most often associated with aggressive mixed CD type [2].

$\mathrm{CD}$ has an unclear etiology, although human herpesvirus 8, HIV coinfection, Epstein-Barr virus, and autoimmune disease have been implicated in the etiology of the multicentric disease (MCD) [3-5]. MCD is usually present with generalized lymphadenopathy with constitutional symptoms, whereas UCD is usually asymptomatic or presents with mass. The sites for UCD include the abdomen, peripheral lymph node, the mediastinum, or the retroperitoneum. Primary organ involvement in UCD is rare and the spleen is the most commonly affected organ, whereas the most common intra-abdominal involved site is the retroperitoneal lymph nodes [6].

Retroperitoneal tumors or masses are usually asymptomatic until they are large enough to cause pressure symptoms. Sometimes, they are detected incidentally. It mimics a variety of pathology from tumor mass to enlarged lymph nodes. Therefore, pre-operative diagnosis remains a challenge and a very high clinical suspicion is needed. As in our case, we thought it to be a distal pancreatic mass or non-functional endocrine tumor. Nagano et al. have reported retroperitoneal UCD mimicking as paraspinal schwannoma [7].

A multidisciplinary approach is often required for proper diagnosis and management [8]. Few characteristic CT findings such as the degree of rim enhancement have been suggested to differentiate it from other pathology [9]. Pre-operative tissue cytology from these masses may be misleading unless a corecut biopsy is performed [10]. It is not performed routinely in our institution in the resectable lesions. As a result, the definitive diagnosis is based on post-operative pathological findings. Although immunohistochemical analysis and virologic workup are suggested for further analysis and treatment [11], it was not feasible in our patient. Again care must also be taken to differentiate UCD from MCD using radiologic techniques, as a treatment for these variants differs significantly.

For UCD, surgical resection can be curative, with longterm, recurrence-free survival as described in the majority of case reports and series [6,12]. Surgical morbidity depends on the size, location, and relation with major vascular structures. Talat et al. have shown that more than $90 \%$ of patients of UCD underwent resective surgery, whereas only $38.9 \%$ of MCD patients underwent resective surgery [6]. Most of these patients underwent diagnostic surgery in the form of peripheral lymph node biopsy or endoscopic biopsy. MCD is usually managed with combination chemotherapy, whereas the role of radiotherapy and antiviral therapy remains unclear [8]. Appropriate follow-up along with radiological assessment should be performed to detect early recurrence. Some authors recommend routine CT yearly for the first 3 years and again at 5 years postoperatively [13].

\section{CONCLUSION}

In this case report, we describe a poorly understood disease that inherently poses diagnostic as well as a therapeutic dilemma for surgeons. Because of the rarity of the disease, evidencebased guideline is unlikely to evolve for the management of this disease. Although some characteristic radiologic features have been cited, a very high clinical suspicion is necessary for pre-operative diagnosis. Surgical resection remains the mainstay of treatment for the unicentric variety, whereas the multidisciplinary approach holds the pivotal role for proper management of a MCD. 


\section{REFERENCES}

1. Castleman B, Iverson L, Menendez VP. Localized mediastinal lymphnode hyperplasia resembling thymoma. Cancer 1956;9:822-30.

2. Chronowski GM, Ha CS, Wilder RB, Cabanillas F, Manning J, Cox JD. Treatment of unicentric and multicentric Castleman disease and the role of radiotherapy. Cancer 2001;92:670-6.

3. Powles T, Stebbing J, Bazeos A, Hatzimichael E, Mandalia S, Nelson M, et al. The role of immune suppression and HHV-8 in the increasing incidence of HIV-associated multicentric Castleman's disease. Ann Oncol 2009;20:775-9.

4. Chen CH, Liu HC, Hung TT, Liu TP. Possible roles of Epstein-Barr virus in Castleman disease. J Cardiothorac Surg 2009;4:31.

5. Muskardin TW, Peterson BA, Molitor JA. Castleman disease and associated autoimmune disease. Curr Opin Rheumatol 2012;24:76-83.

6. Talat N, Belgaumkar AP, Schulte KM. Surgery in Castleman's disease: A systematic review of 404 published cases. Ann Surg 2012;255:677-84.

7. Nagano S, Yokouchi M, Yamamoto T, Kaieda H, Setoguchi T, Hiraki T, et al. Castleman's disease in the retroperitoneal space mimicking a paraspinal schwannoma: A case report. World J Surg Oncol 2013;11:108.

8. van Rhee F, Stone K, Szmania S, Barlogie B, Singh Z. Castleman disease in the $21^{\text {st }}$ century: An update on diagnosis, assessment, and therapy. Clin Adv
Hematol Oncol 2010;8:486-98.

9. Zheng X, Pan K, Cheng J, Dong L, Yang K, Wu E. Localized Castleman disease in retroperitoneum: Newly discovered features by multi-detector helical CT. Abdom Imaging 2008;33:489-92.

10. Strauss DC, Qureshi YA, Hayes AJ, Thway K, Fisher C, Thomas JM. The role of core needle biopsy in the diagnosis of suspected soft tissue tumours. J Surg Oncol 2010;102:523-9.

11. Chan KL, Lade S, Prince HM, Harrison SJ. Update and new approaches in the treatment of Castleman disease. J Blood Med 2016;7:145-58.

12. Bowne WB, Lewis JJ, Filippa DA, Niesvizky R, Brooks AD, Burt ME, et al. The management of unicentric and multicentric Castleman's disease: A report of 16 cases and a review of the literature. Cancer 1999;85:706-17.

13. Williams AD, Sanchez A, Hou JS, Rubin RR, Hysell ME, Babcock BD, et al. Retroperitoneal Castleman's disease: Advocating a multidisciplinary approach for a rare clinical entity. World J Surg Oncol 2014;12:30.

Funding: None; Conflicts of Interest: None Stated.

How to cite this article: Jana K, Das R, Ghosh R, Ray S. Castleman's disease: A case report. Indian J Case Reports. 2020;6(10):572-574. 